\title{
Crop cultivation of Middle Yayoi culture communities (fourth century $B C E-$ first century $C E)$ in the Kanto region, eastern Japan, inferred from a radiocarbon-dated archaeobotanical record
}

\author{
Christian Leipe ${ }^{1}$ (D) Eiko Endo ${ }^{2} \cdot$ Shunsuke Kuramochi ${ }^{3} \cdot$ Mayke Wagner $^{4} \cdot$ Pavel E. Tarasov $^{5}$
}

Received: 10 January 2020 / Accepted: 10 July 2020

(c) The Author(s) 2021, corrected publication, 2021

\begin{abstract}
AMS-dated archaeobotanical assemblages from hearth deposits of Middle Yayoi (fourth century BCE-first century CE) cultural layers of the Maenakanishi site $\left(36^{\circ} 09^{\prime} \mathrm{N}, 139^{\circ} 24^{\prime} \mathrm{E}\right)$ in northern Saitama Prefecture demonstrate that besides rice, foxtail and broomcorn millet were the most important staple crops during the second and first centuries BCE. The reliance on less demanding dry-field crops at Maenakanishi and other Early to Middle Yayoi settlements in north-western Kanto and the Central Highlands in eastern central Japan contrasts with concurrent agricultural production in western and north-eastern (Tohoku) Japan, where rice cultivation generally dominated and millets apparently played a minor role. Two factors, which likely influenced this pattern, are the uneven density distribution and the cultural heterogeneity of indigenous non-agricultural Jomon populations during the formation and spread of the Yayoi culture (tenth/fourth century BCE- $250 \mathrm{CE}$ ) brought to the Japanese islands by farmers from the Asian mainland. In western Japan the spread of rice cultivation was likely promoted by low Jomon population densities. The higher importance of foxtail and broomcorn millet at Maenakanishi may be explained by cultural influence from the northern Central Highlands. Early agricultural communities in this region appear to have preferred these newcomer crops that required less labour and organisational efforts.
\end{abstract}

Keywords Early agriculture $\cdot$ Crop introduction $\cdot$ Oryza sativa (rice) $\cdot$ Setaria italica (foxtail millet) $\cdot$ Panicum miliaceum (broomcorn millet) · East Asia

Communicated by J. Kitagawa.

Electronic supplementary material The online version of this article (https://doi.org/10.1007/s00334-020-00791-1) contains supplementary material, which is available to authorized users.

Christian Leipe

c.leipe@fu-berlin.de

1 Institute for Space-Earth Environmental Research (ISEE), Nagoya University, Research Institutes Building II, Furo-cho, Chikusa-ku, Nagoya, Aichi 464-8601, Japan

2 Center for Obsidian and Lithic Studies, Meiji University, 1-1 Kanda-Surugadai, Chiyoda-ku, Tokyo 101-0064, Japan

3 Kumagaya City Board of Education, Social Education Division, Kumagaya City Konan Cultural Heritage Center, 329 Chiyo, Kumagaya City, Saitama 360-0107, Japan

4 Eurasia Department and Beijing Branch Office, German Archaeological Institute, Im Dol 2-6, 14195 Berlin, Germany

5 Institute of Geological Sciences, Paleontology Section, Freie Universität Berlin, Malteserstraße 74-100, Building D, 12249 Berlin, Germany

\section{Introduction}

During the Yayoi period (tenth/fourth century BCE-250 CE) Japan underwent some of the most fundamental cultural changes in its prehistory. Despite long-term debates about its drivers, it seems most likely that these changes were mainly associated with immigration from the East Asian mainland (Shinoda 2004; Lee and Hasegawa 2011; Steinhaus and Kaner 2016; Takahashi et al. 2019). The substantial population growth and increasing social inequality during the Yayoi period are linked with a fully agricultural lifestyle, which, except in Okinawa and Hokkaido, spread over the Japanese archipelago marking the termination of the preceding Jomon period (Ishikawa 2014). The spread spanned several centuries resulting in a pattern of regional differences in the onset of the Yayoi culture, which is still under debate (Fujio 2017; Saino 2017).

Agriculture was mainly based on the cultivation of several domesticated crops. While some of the grown plants, such as Perilla (beefsteak plant), Lagenaria siceraria (bottle 
gourd), Vigna angularis (adzuki bean), Glycine max (soybean) and Echinochloa esculenta (barnyard millet) may have been domesticated in Japan (Crawford 2011), other, more important staple crops during the Yayoi period, such as Oryza sativa (rice), Panicum miliaceum (broomcorn millet) and Setaria italica (foxtail millet) originated from the Eurasian mainland (Ando 2014; Nasu and Momohara 2016). Today the main criterion used to define the Yayoi culture is the adoption of paddy field rice cultivation (Fujio 2011) and it is a widespread narrative that, once adopted, rice became the major food source and was the main driver of the cultural transformations that occurred over the Yayoi period (Imamura 1996; Ishikawa 2011; Mizoguchi 2013).

On the other hand, various arguments have been presented suggesting that rice has not everywhere and always been the predominant food source across Japan during the earliest stages of the agricultural era (Crawford and Takamiya 1990; Ohnuki-Tierney 1993; Amino 1994; von
Verschuer 2016). This seems to be related to the notable cultural regionality resulting from the overlap of indigenous Jomon communities and spread of Yayoi newcomers (Shitara 2014a; Ishikawa 2017). While western Japan (Fig. 1a) has been recognised as the actual core region of the Yayoi culture with important centres in northern Kyushu and the Kinki region (Fig. 1a), eastern Japan is often identified as a peripheral area (Hosoya 2009; Mizoguchi 2013). Indeed, most evidence for typical Yayoi cultural features, such as substantial population growth, ritual practices using bronze objects, social hierarchy and the emergence of authorities and large regional centres, is limited to western Japan (Mizoguchi 2013; Steinhaus and Kaner 2016). This also applies to rice-dominated crop production, although recent studies suggest that in some places in the western domain, which appear to be suitable for wet-field rice cultivation, foxtail and broomcorn millet played a substantial role (Endo 2012; Endo and Ito 2013; Nakamura and Nakazawa 2014).

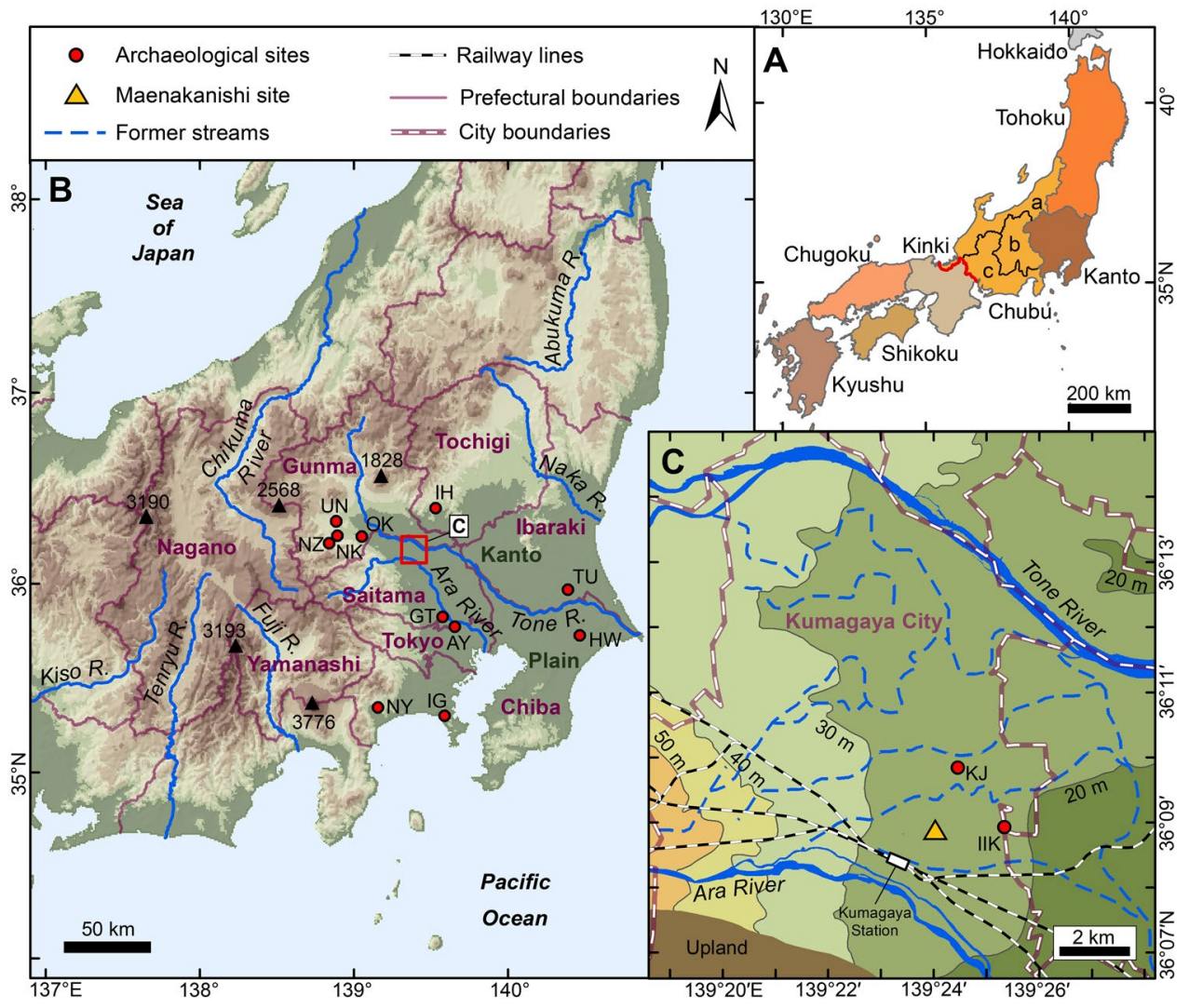

Fig. 1 Map compilation showing $\mathbf{A}$ the main regions of Japan including the subdivisions of Chubu ( $a$-Hokuriku, $b-$ Central Highlands, $c$-Tokai) and the boundary (red line) between Chubu and Kinki separating the Yayoi cultural regions of eastern and western Japan according to Mizoguchi (2013), B the topography and major rivers of Central Honshu with the study region in the north-western part of the Kanto Plain (red square); $\mathbf{C}$ the Maenakanishi archaeological site, the two main regional rivers and the estimated course of former anabranches and streams. Contour lines and coloured areas (green to light brown) illustrate elevation units of the river flood plains and dark brown area indicates loamy upland (after Kumagaya City Board of Education 2015). Location of other archaeological sites mentioned in the text including $A Y$ Asukayama, GT Goboyama and Tagoyama, $H W$ Hanawadai, IIK Ikegami-Ikemori and Koshikida, IG Ikego, $I H$ Izuruhara, $K J$ Kitajima, $N Y$ Nakayashiki, $N Z$ Nakazatohara, $N K$ Nanokaichikannonmae, $O K$ Oki 2, TU Tonouchi, UN Uwahitomi and Nakanoyahara 
In eastern Japan that is regarded as peripheral the situation seems to be more complex (Shitara 2014b). In some regions of Kanto (Fig. 1a and b) there is evidence that rice did not always play a dominant role in agricultural production (Shitara and Takase 2014; Endo 2015, 2019). Regarding Tohoku (Fig. 1a) long-standing concepts about Yayoi crop cultivation predominated by dry-field crops (Terasawa 1986; Crawford and Takamiya 1990) are challenged by recent archaeobotanical data (Takase 2011, 2018; Nishimura et al. 2018; Sato et al. 2018) indicating an opposite pattern with most evidence for rice and few traces of millet production. Therefore, the Yayoi food production and subsistence economy should be studied on a regional level. While analyses of seed impressions on pottery have been extensively conducted in Japan (Nasu and Momohara 2016 and references therein), utilisation of systematic flotation is limited (Kaner and Yano 2015) and data on Yayoi diet throughout the archipelago is still scarce (Barnes 2015; Nasu and Momohara 2016).

In the current paper we present the results of an archaeobotanical study conducted at the Maenakanishi archaeological site in Kanto, eastern Japan (Fig. 1). The macrobotanical remains derived from deposits of ten hearths each located inside an individual pit house are used to reconstruct the food production economy of Middle Yayoi culture communities in Kanto. For chronological assessment of the finds and temporal correlation of the different sections, a representative set of domesticated plant seeds was selected for absolute age determination using the AMS radiocarbon $\left({ }^{14} \mathrm{C}\right)$ dating method. Our results are then compared with other archaeobotanical records available from Kanto and beyond. Unless otherwise stated, Jomon and Yayoi cultural chronologies are given according to Matsumoto et al. (2017) and Steinhaus and Kaner (2016), respectively.

\section{Site setting and archaeological context}

The Maenakanishi archaeological site complex $\left(36^{\circ} 09^{\prime}\right.$ $\mathrm{N}, 139^{\circ} 24^{\prime} \mathrm{E}$; $24 \mathrm{~m}$ a.s.l.; Fig. 1) lies in the eastern part of Kumagaya City located in northern Saitama Prefecture in the north-western part of the Kanto Plain in the eastern part of Honshu Island. The site complex is situated between two of the largest rivers of the Kanto Plain, the Tone River (Tonegawa) in the north and the Ara River (Arakawa) in the south, both flowing in a south-easterly direction into the Pacific Ocean (Fig. 1). The site is located in the area where the distance between these two major rivers is shortest. The entire area has fertile alluvial soils and is almost flat. It was traversed by numerous smaller rivers and streams until pre-modern times. The location of the settlement site appears to have been favourable for paddy field rice cultivation and an ideal base for long-distant exchange activities. Although a total of 88 rice paddy fields have been identified at the Kitajima site, which is located ca. $2 \mathrm{~km}$ to the north of Maenakanishi (Fig. 1c) and belongs to the same pottery type (Kitajima type), none have been found within the current extent of the Maenakanishi site complex.

The Kumagaya City archaeological site database lists 91, 28 and 211 sites associated with the Jomon, Yayoi and Kofun cultures, respectively (Konan Cultural Heritage Center 2018). At the Maenakanishi site, which spans an area of $316,500 \mathrm{~m}^{2}$, numerous archaeological surveys have been conducted, mostly by the Kumagaya City Board of Education in the course of infrastructure projects since 1996. These surveys have produced an extensive archaeological record, which indicates a long human occupation spanning several cultural phases, i.e. from the Yayoi to the Edo (1603-1868 CE) period (Kanto Yayoi Culture Research Group 2014). Most of the Maenakanishi archaeological record is associated with the Yayoi culture. Based on pottery typology, the occupation phase has been dated to between the middle Middle Yayoi (ca. 100 BCE) and the early Late Yayoi (ca. $100 \mathrm{CE}$ ) with the most prosperous phase during the late Middle Yayoi (Kumagaya City Buried Cultural Heritage Center 2008). During this time a large settlement of ca. 30 ha existed, which is one of the largest known of the Yayoi culture in Kanto. Until 2018, 60 pit houses, 30 ditches, 20 burial mounds, 13 jar burials and one grave assigned to the Yayoi culture were found. In addition, a number of other, smaller Yayoi culture sites have been excavated in the vicinity of Maenakanishi (Fig. 1c). The pottery assemblages show connections of the inhabitants with Yayoi populations of other regions. Pottery from southern Tohoku (Kawaramachiguchi type), southern Kanto (Miyanodai type) and the northern Central Highlands, i.e. northern Nagano Prefecture, (Kuribayashi type) (Fig. 1a and b) has been excavated. The continuously increasing amount of Kuribayashi type pottery over the late Middle Yayoi period has been interpreted as increasing cultural influence by migrations from and/or exchange with the northern Central Highlands (Fig. 1a) (Kanto Yayoi Culture Research Group 2014).

The deposits analysed in the present study come from sections 2 and 3 of the 2018 archaeological survey performed in the northern part of Maenakanishi $\left(36^{\circ} 08^{\prime} 55^{\prime \prime}\right.$ N, $139^{\circ} 24^{\prime} 08^{\prime \prime}$ E; Fig. 2) covering an area of 380 and 800 $\mathrm{m}^{2}$, respectively. The survey documented in the unpublished excavation report has identified 26 house pits, of which 11 pits (SI2-01-11) are located in section 2 and further 15 pits (SI3-01-15) are located in section 3 (Fig. 2). Inside eight pits hearth deposits were identified. Together with a concentration of post-holes typically interpreted as remains of a pillared building, SI3-06 seems to be spatially separated from the area to the north by a fence structure (SA3-01) and to the south by a former stream. 


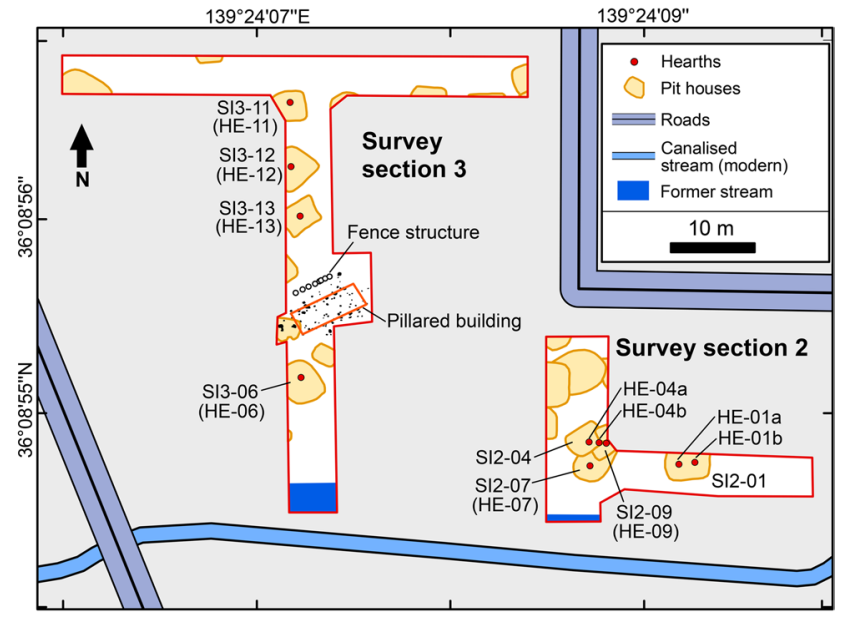

Fig. 2 Simplified sketch map of the Maenakanishi 2018 archaeological survey sections 2 and 3 with locations of post-holes (black polygons) and the estimated position of the associated pillared building (orange rectangle), the fence structure SA3-01 (black circles) and pits (labelled as SI2/3) from which hearth (labelled as HE) deposits were archaeobotanically analysed

\section{Material and methods}

Samples for flotation were collected from each of the ten identified hearths (Fig. 2) within survey sections 2 and 3. All of them were located at floor level inside pit houses including SI2-01, SI2-04, SI2-07, SI2-09, SI3-06, SI311, SI3-12 and SI3-13. Except for SI2-01 and SI2-04, which contained two hearths, all pits contained one hearth (Fig. 2). The two hearths in SI2-04 were located within a distance of about $2 \mathrm{~m}$. Extraction of the light fraction of the ten sediment samples was done using bucket flotation and two sieves with a mesh size of 1,000 and $250 \mu \mathrm{m}$ for sample fractionation. Only carbonised plant remains were considered for identification. To avoid counting fragments from the same seed more than once we omitted fragments that comprised less than $50 \%$ of their original size. This approach prevents artificial inflation of the total counts and serves the same function as minimum number of individual estimates. For photographic documentation of selected seeds, we used a Keyence VHX-2000 digital microscope.

Selected carbonised seeds of domesticated plants were directly dated using the AMS ${ }^{14} \mathrm{C}$ dating facilities at the Poznan Radiocarbon Laboratory and the Division of Chronological Research at the Institute of Space-Earth Environmental Research of Nagoya University. For conversion of ${ }^{14} \mathrm{C}$ dates to calendar ages OxCal v4.3.2 software (Bronk Ramsey 1995) and the calibration curve Intcal13 (Reimer et al. 2013) were used.

\section{Results}

\section{Archaeobotanical analysis}

Of the 761 carbonised seeds extracted from the ten hearth deposit samples a total of 719 were identified and assigned to 18 different plant taxa (Leipe et al. 2020a). The recorded total assemblage of all samples reflects a mix of remains of ruderal plants, such as Rumex and Chenopodium, a foraging component including wild taxa, such as Rubus, Sambucus and Vitis as well as cultivated plants. The latter contains beefsteak plant, adzuki bean and cereal crops (Table 1; Fig. 3) including rice, foxtail and broomcorn millet. While the latter contains Perilla $(n=2)$ and Vigna angularis $(n=2)$ are few, seeds of cereals are more abundant with the majority identified as Oryza $(n=537)$ followed by Setaria $(n=124)$ and Panicum $(n=10)$ millet. In addition, two clusters of rice husks, each comprising approximately 10-20 specimens, were recorded in the hearth sample from pit SI3-06.
Table 1 Sample-specific total counts of carbonised domesticated cereal grains and floated litres from hearth deposits at the Maenakanishi site (Maenakanishi 2018 archaeological survey sections 2 and 3), Kumagaya City, Japan

\begin{tabular}{lllrrll}
\hline Sample ID & $\begin{array}{l}\text { Sample } \\
\text { vol. (L) }\end{array}$ & Pit house/hearth ID & Rice & Foxtail millet & $\begin{array}{l}\text { Broom- } \\
\text { corn millet }\end{array}$ & Ratio rice/millets \\
\hline F-04a & 7 & SI2-04/HE-04a & 13 & 10 & 1 & 1.18 \\
F-04b & 5 & SI2-04/HE-04b & 10 & 9 & & 1.11 \\
F-01a & 6 & SI2-01/HE-01a & 4 & 11 & 1 & 0.33 \\
F-01b & 4 & SI2-01/HE-01b & 2 & 9 & & 0.22 \\
F-07 & 5 & SI2-07/HE-07 & 1 & 3 & 1 & 0.25 \\
F-09 & 5 & SI2-09/HE-09 & 3 & 11 & 1 & 0.25 \\
F-06 & 24 & SI3-06/HE-06 & 484 & 40 & 2 & 11.52 \\
F-11 & 10 & SI3-11/HE-11 & 19 & 27 & 4 & 0.61 \\
F-12 & 8 & SI3-12/HE-12 & & 3 & & 1 \\
F-13 & 6 & SI3-13/HE-13 & 1 & 1 & & \\
\hline
\end{tabular}

Location of flotation samples is indicated by related pit house and hearth IDs (Fig. 2). For the complete archaeobotanical dataset the reader is referred to the supplementary material 
Fig. 3 Examples of carbonised grains of 1 Panicum miliaceum (broomcorn millet) and $\mathbf{2}$ Setaria italica (foxtail millet) in ventral (a), dorsal (b) and lateral (c) view and of $\mathbf{3 , 4}$ Oryza sativa (rice) in lateral (a) and dorsal (b) view from the analysed Yayoi culture hearth deposits of the Maenakanishi site, western Kanto, Japan (Fig. 1); scale bars $=1 \mathrm{~mm}$
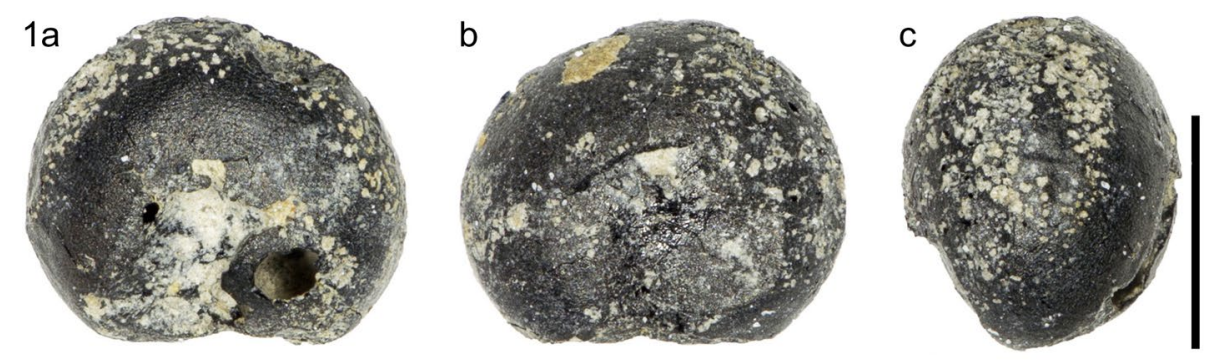

$2 a$

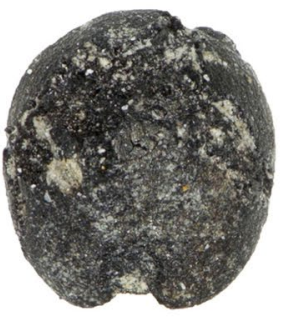

b
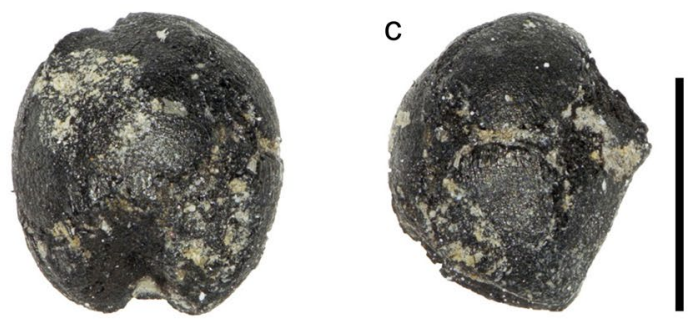

$4 a$
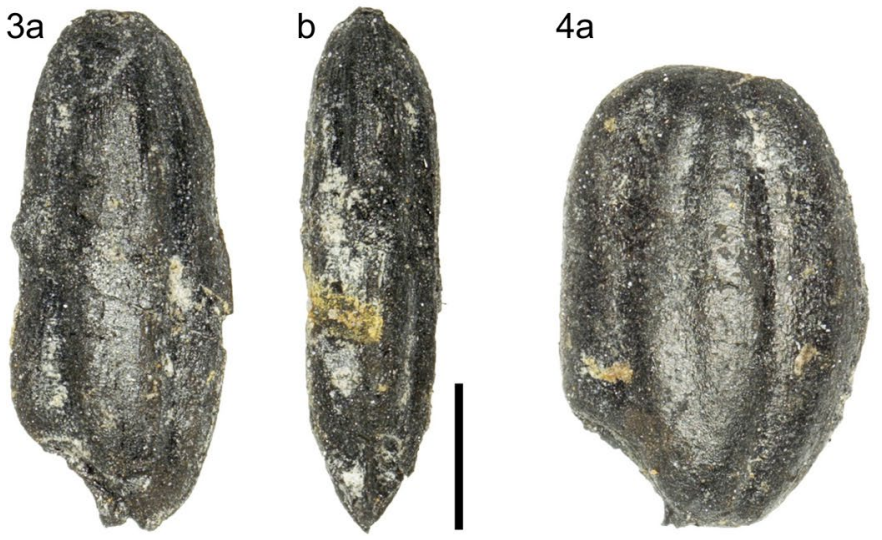

b

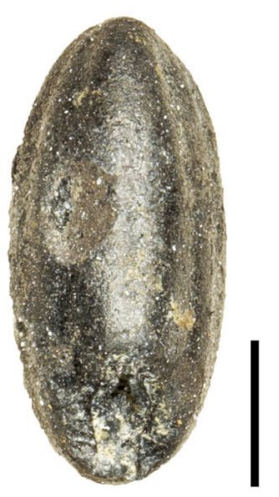

Looking at the cereal assemblages per sample (i.e. hearth) there is an obvious difference between the one from SI3-06 and those from other buildings. First, the number of identified cereal grains $(n=526)$ is much higher than that of the nine other samples, in which the number of specimens ranges between 2 and 50 . Second, there is a difference between the ratio of rice and millets (Fig. 4). In the sample from SI3-06 the number of rice grains is about 10 times higher (92\%) than that of millets, while in the other samples the proportion of millets is generally higher (46 to 82\%). Except for the two hearths located in SI2-04, where the number of millet grains is slightly below that of rice, millets dominate over rice. Although the rice/millets ratios for the hearths from SI2-07, SI3-12 and SI3-13 are less significant due to the small cereal grain assemblages ranging between 2 and 5, there is a general bias towards millets. Another unique attribute of the analysed hearth deposits from SI3-06 is the concentration of pottery sherds extracted during flotation. a

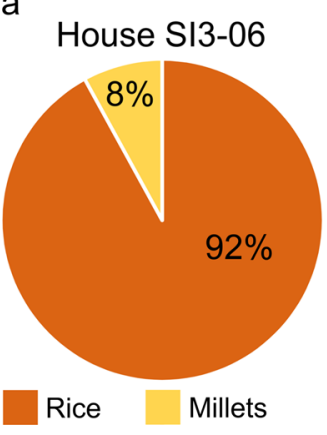

b Remaining houses

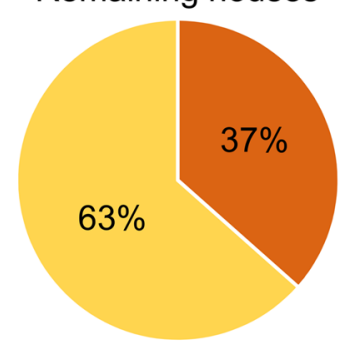

Fig. 4 Charts illustrating the ratio between rice and millets (Setaria italica and Panicum miliaceum) in the assemblages from a SI3-06 and $\mathbf{b}$ the remaining seven buildings from which hearth deposits were analysed (Fig. 2) 


\section{Radiocarbon dating}

For dating of the archaeobotanical assemblages we have selected nine seed samples representing six flotation samples from hearths located in five buildings (Table 2, Fig. 5). The samples consisted of either single grains of rice or broomcorn millet or 3-9 grains of foxtail millet. The confidence intervals of the calibrated ages of all nine samples range between 352 BCE and 127 CE (68\% range) and $359 \mathrm{BCE}$ and $239 \mathrm{CE}$ (95\% range). The oldest date (D-04b) based on foxtail millet from hearth HE-04b shows a median age of $239 \mathrm{BCE}$, while the youngest date (D-06-1) representing a rice grain from hearth HE-06 (pit house SI3-06) has a median age of $10 \mathrm{CE}$.

\section{Interpretation and discussion}

In terms of the rice/millets ratio, the seed assemblage from the hearth of SI3-06 represents an exception. The number of identified rice grains is extensive and more than ten times higher than those of millets. In addition, together with the pillared building, SI3-06 forms a spatial complex that is separated from the rest of the pit houses within survey section 3 by the fence structure SA3-01. We argue that SI3-06 had a special function, and thus differs from the other pits that likely represent dwellings of commoners. These issues are addressed in the section 'Rice versus millet cultivation' below following the discussion on the absolute and relative chronologies of the analysed hearth deposits. The functionality of rice and the spatially separated site complex is addressed in a separate paper (Leipe et al. 2020b), which combines the current archaeobotanical record with archaeological data from the studied survey sections.

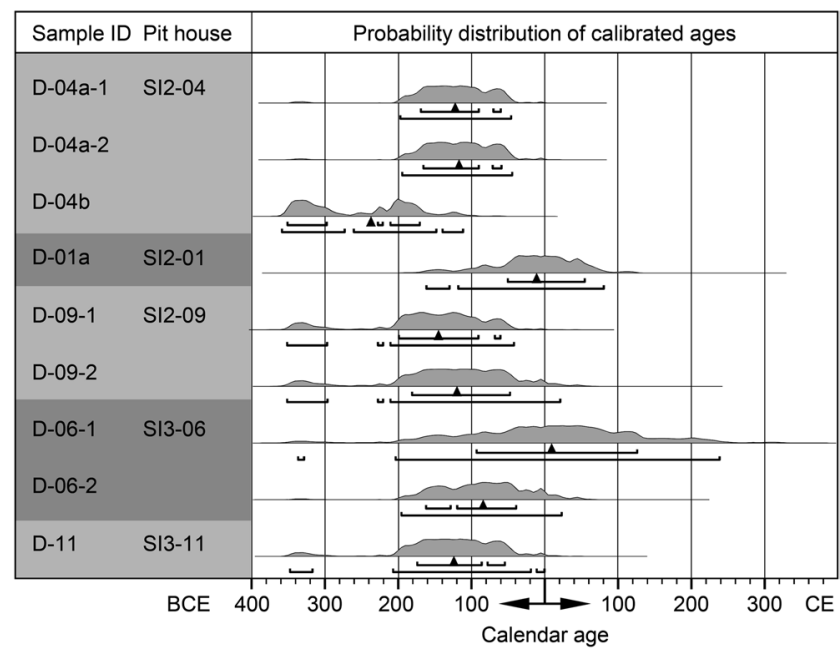

Fig. 5 Probability densities at 68\% (upper square brackets) and $95 \%$ (lower square brackets) confidence level and medians (arrows) of calibrated AMS ${ }^{14} \mathrm{C}$ dates (Table 2) of carbonised rice and millet grains from hearth deposits (Fig. 2) at the Maenakanishi site

\section{Chronology of archaeobotanical records}

The obtained ${ }^{14} \mathrm{C}$ datings (Table 2) are the first available absolute age determinations for the Yayoi cultural layers of Maenakanishi. The probability distributions of the calibrated ages (Fig. 5) suggest that SI2-04, SI2-09 and SI3-11 existed more or less around the same time during the second century BCE (see Fig. 2 for location of pits and hearths). Dating D-04b from the second hearth (HE-04b) within SI2-04 reflects a house that existed sometime between 352 and 171 BCE (68\% confidence interval), i.e. earlier, at the same location. Referring to the calibrated age ranges, SI2-04 postdates the pit house that is related to hearth HE-04b by 0 to 161 years (95\% confidence interval) or 1 to 182 years (68\% confidence interval). Although the archaeological record shows that SI2-09 existed before SI2-04 (and hearth

Table 2 AMS ${ }^{14} \mathrm{C}$ dates and calibrated ages of carbonised millet and rice grains from the analysed hearth deposits of the Maenakanishi site

\begin{tabular}{|c|c|c|c|c|c|c|c|}
\hline Sample & Lab.code & Dated material & Flotation sample/hearth & ${ }^{14} \mathrm{C}$ age (years BP) & Cal age, $1 \sigma$-range & Cal age, $2 \sigma$-range & Median age \\
\hline D-04a-1 & Poz-113871 & Oryza sativa & F-04a/HE-04a & $2,100 \pm 30$ & 170-61 вСЕ & $198-47$ все & 123 вСЕ \\
\hline D-04a-2 & Poz-114334 & P. miliaceum & F-04a/ HE-04a & $2,095 \pm 30$ & $166-60$ вСЕ & $195-45$ все & 117 BCE \\
\hline$D-04 b$ & Poz-114335 & Setaria italica & F-04b/ HE-04b & $2,165 \pm 30$ & $352-171$ вСЕ & 359-112 вСЕ & 239 вCE \\
\hline D-01a & NUTA2-21,202 & Oryza sativa & F-01a /HE-01a & $2,007 \pm 50$ & $51 \mathrm{BCE}-55 \mathrm{CE}$ & $162 \mathrm{BCE}-81 \mathrm{CE}$ & $11 \mathrm{BCE}$ \\
\hline D-09-1 & NUTA2-21,204 & Oryza sativa & F-09/HE-09 & $2,120 \pm 40$ & 200-61 вСЕ & $352-43$ вСЕ & 146 ВСЕ \\
\hline D-09-2 & NUTA2-21,205 & Setaria italica & F-09/HE-09 & $2,095 \pm 50$ & $182-48$ вСЕ & 352 вСE -22 CE & 120 ВСЕ \\
\hline D-06-1 & NUTA2-21,206 & Oryza sativa & F-06/HE-06 & $1,981 \pm 90$ & 94 BCE-127 CE & 337 ВСЕ-239 СЕ & $10 \mathrm{CE}$ \\
\hline D-06-2 & NUTA2-21,209 & Setaria italica & F-06/HE-06 & $2,065 \pm 40$ & $163-40$ ВСЕ & 196 в & $85 \mathrm{BCE}$ \\
\hline D-11 & NUTA2-21,208 & Setaria italica & F-11/HE-11 & $2,101 \pm 40$ & $175-55$ всЕ & $348-1$ ВСЕ & $125 \mathrm{BCE}$ \\
\hline
\end{tabular}

Sample origin is indicated by related flotation sample and hearth ID (Table 1, Fig. 2). Calibration was performed using OxCal v4.3.2 (Bronk Ramsey 1995) and the calibration curve Intcal13 (Reimer et al. 2013) 
HE-04b), the calibrated age ranges suggest that the temporal gap between both constructions was small. Considering the $68 \%$ confidence intervals this period ranges between 0 and 30 years. On the other hand, SI2-01 seems to have been in use later, i.e. sometime between the late first century $\mathrm{BCE}$ and early first century $\mathrm{CE}$, than the other dated buildings in the same survey section. The age ranges of D-06-1 and D-06-2 derived from the same hearth indicate use of SI3-06 over a longer period, up to 300 years according to the $68 \%$ confidence intervals. However, D-06-1 is less robust due to a relatively large error range (95.1\% confidence interval from $204 \mathrm{BCE}$ to $239 \mathrm{CE}$ ). The dating results in sum suggest that pit house SI3-06 is contemporary with the surrounding buildings outside the enclosed area. Given the evidence for the coexistence of SI3-06 and the pillared building within the space enclosed by the fence structure, this site complex as a whole is associated with the remaining pit houses in both survey sections. In addition, it appears that building SI3-06 and the enclosed space including the pillared building were used over a longer, possibly the entire, occupation period, as indicated by the dates.

In sum, the calibrated ages suggest that the excavated area was continuously occupied by Yayoi culture people at least from around the late third century BCE until the end of the first century вСE. Our data shift the Maenakanishi pottery typologically assigned to middle Middle Yayoi to early Late Yayoi between ca. 100 BCE and 100 CE (Kumagaya City Buried Cultural Heritage Center 2008), slightly back in time. Based on our dates, occupation of the studied sections of Maenakanishi started at least around the early/middle Middle Yayoi transition ca. 200 все. Our results demonstrate that understanding of temporal relations between different archaeological sites may be improved by absolute age determination based on AMS radiocarbon dating of short-lived terrestrial plant material.

\section{Rice versus millet cultivation}

The data obtained in the current study show that rice and millets were the main cultivated crops at Maenakanishi ca. 200-1 вCE. Excluding the record from SI3-06, the number of identified millet grains found in the hearth deposits is generally higher than that of rice. Regarding the recorded grains of these crops, $63 \%$ belong to either foxtail or broomcorn millet and 37\% to rice (Fig. 4). This suggests that millets were a substantial part of the local population's diet. These findings concur with the results based on the analysis of seed impressions on pottery from Yayoi cultural layers of archaeological sites in the Kumagaya City area and partly also with sites in other parts of western Kanto. In several studies (Nakayashiki Site Excavation Project Team 2010; Endo 2011, 2014, 2015, 2016, 2017, 2018, 2019; Shitara and Takase 2014) pottery fragments of late Early (ca. fifth-fourth century BCE) to Middle Yayoi context from archaeological sites in Kanto including Maenakanishi were analysed. The most commonly identified impressions are that of rice, foxtail millet and broomcorn millet grains. The number of identified seed impressions per site spans from 2 to 51 . Considering only those for which $\geq 10$ impressions are available, there are 16 sites for which rice/millet grain ratios may be compared (Table 3; Fig. 1). At 8 sites millet impressions and at 8 sites rice impressions dominate. At Maenakanishi and Kitajima, located ca. $2 \mathrm{~km}$ to the north of Maenakanishi (Fig. 1c), millet impressions exceed those of rice, thus corroborate our results. The most prosperous period of both sites (late Middle Yayoi period) belongs to the Kitajima type of the regional pottery typology. On the other hand, pot sherds from sites Ikegami-Ikemori and Koshikida (Fig. 1c) located ca. $2 \mathrm{~km}$ east of Maenakanishi belonging to the Ikegami type (middle Middle Yayoi period) have more rice than millet grain impressions, thus demonstrate an opposite pattern. The suggested difference in rice/millets preference between Maenakanishi/Kitajima and IkegamiIkemori/Koshikida may represent changing crop cultivation patterns in the same area over a relatively short period, i.e. 1-2 centuries. Regarding Maenakanishi, agreement is also manifested for the preference of foxtail over broomcorn millet. The total ratio of carbonised grains is 124 to 10 (Table 1), while the impression analysis identified all millet grains $(n=31)$ as foxtail millet (Table 3 ).

Further support for millet-dominated farming practices in several areas is provided by archaeobotanical analyses at the Yayoi culture Nakayashiki site in south-western Kanto (Fig. 1b), one of the earliest known Yayoi sites in Kanto. Radiocarbon dating of selected organic remains including rice (oldest rice dates to 507-404 $\mathrm{BCE}, 68 \%$ error range of calibrated age) places these layers to the late phase of the Early Yayoi period (Yamamoto and Koizumi 2005). Archaeobotanical datasets derived from flotation conducted during several excavation campaigns reveal more millet than rice grains (Nakayashiki Site Excavation Project Team 2008, 2010). Analyses of earth pit sediments of cultural layers dated to the late Early and early Middle (ca. fourth-third century BCE) Yayoi period identified in total 556 carbonised grains of rice and 2649 grains of millets. Among them the number of foxtail millet grains (2577) is notably higher than that of broomcorn millet (72). Results of a seed impression analysis (Nakayashiki Site Excavation Project Team 2010) did not reveal rice grain impressions and recorded slightly more broomcorn $(n=21)$ than foxtail $(n=15)$ millet grains. Although dating to a later period (Late Yayoi), Tagoyama (Fig. 1b) is another site in south-western Kanto at which high numbers of carbonised millet remains were found. Here 81,481 rice and 194,993 millet grains were extracted from deposits of a single pit house (Ogata 1998). All millet grains were assigned to foxtail millet. 
Table 3 Results of seed impression analyses of pottery sherds from late Early-Middle Yayoi cultural sites in western Kanto

\begin{tabular}{|c|c|c|c|c|c|c|c|}
\hline Site & $\begin{array}{l}\text { Location (city/ward, } \\
\text { prefecture) }\end{array}$ & $\begin{array}{l}\text { Yayoi pottery typol- } \\
\text { ogy }\end{array}$ & Rice & Foxtail millet & $\begin{array}{l}\text { Broom- } \\
\text { corn } \\
\text { millet }\end{array}$ & Dominant crop & Reference \\
\hline Asukayama & Kita, Tokyo & late Middle & 11 & & 1 & Rice & Endo (2018) \\
\hline Goboyama & Wako, Saitama & late Middle-Late & 17 & 4 & 6 & Rice & Endo (2014) \\
\hline Hanawadai & Tako, Chiba & early-middle Middle & 8 & 2 & 2 & Rice & Endo (2019) \\
\hline Ikegami-Ikemori & Kumagaya, Saitama & middle Middle & 22 & 4 & 1 & Rice & Endo (2019) \\
\hline Ikego & Zushi, Kanagawa & late Middle & 28 & 2 & 5 & Rice & Endo (2018) \\
\hline Izuruhara & Sano, Tochigi & $\begin{array}{l}\text { early Middle-middle } \\
\text { Middle }\end{array}$ & 10 & 6 & 3 & Rice & Endo (2014) \\
\hline Kitajima & Kumagaya, Saitama & late Middle & 10 & 20 & 1 & Millet & Endo (2014) \\
\hline Koshikida & Kumagaya, Saitama & middle Middle & 15 & 3 & 1 & Rice & Endo (2019) \\
\hline Maenakanishi & Kumagaya, Saitama & late Middle & 17 & 31 & & Millet & Endo (2014) \\
\hline Nakanoyahara & Tomioka, Gunma & $\begin{array}{l}\text { early Middle-middle } \\
\text { Middle }\end{array}$ & 3 & 12 & 25 & Millet & $\begin{array}{l}\text { Shitara and Takase } \\
\text { (2014) }\end{array}$ \\
\hline Nakayashiki & Oi, Kanagawa & $\begin{array}{l}\text { late Early-early } \\
\text { Middle }\end{array}$ & & 15 & 21 & Millet & $\begin{array}{l}\text { Nakayashiki } \\
\text { Site Excavation Pro- } \\
\text { ject Team (2010) }\end{array}$ \\
\hline Nakazatohara & Tomioka, Gunma & late Early & & 6 & 17 & Millet & Endo (2017) \\
\hline $\begin{array}{l}\text { Nanokaichikannon- } \\
\text { mae }\end{array}$ & Annaka, Gunma & early Middle & & 10 & 8 & Millet & Endo (2015) \\
\hline Oki 2 & Fujioka, Gunma & late Early & 1 & 7 & 13 & Millet & Endo (2011) \\
\hline Tonouchi & Inashiki, Ibaraki & early-late Middle & 12 & & 1 & Rice & Endo (2019) \\
\hline Uwahitomi & Annaka, Gunma & $\begin{array}{l}\text { late Early-middle } \\
\text { Middle }\end{array}$ & & 8 & 10 & Millet & Endo (2016) \\
\hline
\end{tabular}

Archaeological site locations are indicated in Fig. 1

In sum, the available data corroborates our interpretation on the crop cultivation strategies at Maenakanishi during the analysed time period and suggests that millets were at least a substantial if not the main plant food there and at other archaeobotanically studied sites of the late Early and Middle Yayoi culture in Kanto. Given the inhomogeneous results in terms of rice/millet grain impression ratios (Table 3), it seems that even on the Kanto spatial scale differences in agricultural strategies have existed among contemporaneous sites and populations, which is supported by the findings of Ishikawa (1998), who identified four concurrent regional cultures in Kanto during the Middle Yayoi period based on pottery types, settlement styles and stone, iron and ritual objects. The available archaeobotanical data suggests that rice was rather preferred in the coastal southern and southwestern parts of Kanto, while in the more inland located areas in the northwest crop preference was shifted towards millets. It is likely that the differences in the rice/millets preferences were controlled by immigrations from different regions, such as Tokai, northern Central Highlands and Tohoku, which are suggested by changing cultural assemblages at Maenakanishi (Kanto Yayoi Culture Research Group 2014) and other sites (Ishikawa 2008) in Kanto. A trend in crop preferences is also observed on the temporal scale. Dividing the sites for which archaeobotanical records are available (sites in Table 3 and Tagoyama site) at the early Middle/middle Middle Yayoi boundary 6 out of 9 sites dating to the earlier period are dominated by millets and 8 out of 13 sites dating to the later period are dominated by rice. This suggests that there is also a trend towards rice preference over time (i.e. from the Early/early Middle to the middle Middle/late Middle Yayoi period).

For Maenakanishi and Kitajima there seems to be a general preference of foxtail millet over broomcorn millet. Liu et al. (2009) pointed out that local climate could be the main factor that determines the preference between these two crops, as broomcorn millet has lower water requirements and a shorter life-cycle than foxtail millet. Regional variation in the cultivation of both crops during the Chinese Neolithic may be inferred from available data. While foxtail millet was more commonly cultivated in moister regions, such as the eastern, lower-elevated parts of the Yellow River region and north-western Yunnan (Underhill 1997; Lee et al. 2007; Dal Martello et al. 2018), broomcorn millet was commonly grown in drier areas, such as the western, higher-elevated parts of the central Yellow River region and the Liao River region of north-eastern China (Liu et al. 2009; Zhao 2011). Archaeobotanical assemblages reported from Chulmun/Mumun cultural layers of three archaeological sites from the humid south-eastern coast of the Korean 
Peninsula (Crawford and Lee 2003) show the same pattern and predominance of foxtail millet over broomcorn millet grains. The dominance of foxtail millet in the samples from Maenakanishi and other sites in Kanto is in line with the geographical pattern of millet cultivation in eastern Asia and further substantiates the assumption that the preference for one crop over another was controlled by climate conditions that are humid year-round over the Japanese archipelago. On the other hand, the preference for foxtail millet may not apply universally to the whole study region. Evidence for broomcorn millet preference at other late Early-Middle Yayoi sites (Table 3) points to a more complex pattern of millet cultivation without a clear preference for one of the two crops. It is possible that the variance in the available data also reflects other factors than climate (e.g. culinary preferences). However, the existing archaeobotanical data mainly comes from seed impression analyses with total counts for the major crops (rice, foxtail and broomcorn millet) seldomly reaching 30 grains. Further studies are needed to obtain a better understanding of the spatio-temporal millet cultivation patterns of early agricultural societies within and beyond the study region.

Our findings contradict the conventional image of farming during the Yayoi period in which rice was the main staple crop. However, it has been widely recognised that, apart from rice, Yayoi culture populations cultivated a broad variety of crops that were either introduced from the Asian mainland or already domesticated and grown by Jomon populations (Crawford 2011). The notion of the dietary importance of rice is likely influenced by long-standing discussions on social, cultural and economic aspects of rice cultivation. Rice has been identified as the impetus for the emergence of social stratification that later led to the formation of the first Japanese state (Ishikawa 2011; Mizoguchi 2013; Kaner and Yano 2015). This development is closely linked with ritual and religious practices related to rice growing that are believed to have appeared during the Yayoi period (Terasawa 2000) and formed precursory practices of religious traditions that are today often summarised as Shinto (Breen and Teeuwen 2010).

The opinions within the archaeological community about the role of rice in the diets of prehistoric and early historic Japanese populations have been controversial and debates continue (see Ohnuki-Tierney 1993; von Verschuer 2016 for detailed reviews). First criticism about the view that rice had been the main food arose in the 1980s and was mostly based on written evidence for subsistence economies during medieval times. As for the discussion regarding the Yayoi period, one prominent study rejecting the predominance of rice is that of Terasawa and Terasawa (1981), which estimates that between the third century BCE and second century CE rice did not contribute more than $50 \%$ to the caloric intake and that tubers, shoots, acorns and dry-field crops (such as millets) must have played an important role in diet. Whether or not such quantitative estimates are correct, the study provides additional evidence for the importance of dry-field crops. Despite frequent doubts that millets could have fed the growing Yayoi population (Negita 2000), it has been proven that it was capable of promoting the development of highly complex agrarian societies and feeding large populations. In northern China (i.e. the lower/middle Yellow River region) where millets were apparently domesticated, they were increasingly grown from ca. 6000 вСЕ and supported a quasi-exponential increase in archaeological sites (Wagner et al. 2013; Hosner et al. 2016) and population growth (Leipe et al. 2019) and eventually the rise of Chinese civilisation (Wagner and Tarasov 2014).

The available archaeobotanical data from Kanto argue against a single Yayoi subsistence model and substantiate the hypothesis by Crawford and Takamiya (1990) that the Yayoi diet is marked by regional differences. This is in accordance with the variety of natural environments across the Japanese islands (Yoshino 1980) and the regional cultural diversity of the preceding Jomon period that amalgamated with cultural traits from the Asian mainland to form a heterogeneous 'Yayoi cultural landscape' (Ishikawa 2017). In view of the available evidence we postulate that in Japan the spread/ adoption of an agricultural lifestyle in which rice was not the predominant crop is related to the distribution pattern of the indigenous hunter-fisher-gatherer populations of Final Jomon (ca. 1300-tenth/fourth century BCE). Paddy field rice cultivation was generally more substantial in the Yayoi core region of western Japan compared to eastern Japan. In fact, the boundary between these two regions as defined by Mizoguchi (2013) roughly corresponds to the biogeographical boundary (Yoshioka 1973) between the environmentally productive temperate deciduous forest zone to the east, which was the preferred settlement area of Jomon populations, and the less productive evergreen forest zone to the west with evidence for fewer Jomon settlements (Koyama 1978; Barnes 2015). This boundary also parallels the line suggested by Akazawa (1986) to mark the spatial limit of the first phase (simultaneous with the Early Yayoi period) of the eastward spread of rice cultivation which, according to Kanaseki and Sahara (1978), took place relatively quickly. It seems that 'rejection' of rice-based agriculture/subsistence economy correlates with Late/Final Jomon settlement (and population) density, which, according to the data presented by Koyama (1978), roughly followed an ascending gradient from west (Kyushu) to east (Kanto) and further on towards the north (Tohoku).

A special case is represented by the Tohoku region from where evidence for a late Yayoi culture onset, i.e. late acceptance of crop cultivation dating to sometime between 450 and 200 вСе (Kunikita 2012; Kobayashi 2017), has been reported. Final Jomon cultural layers of different sites, such 
as the Kamegaoka (Sato 1984), Tareyanagi and Sunazawa (Saino 2005) sites in Aomori Prefecture provide evidence for wet-field rice cultivation by existing Jomon populations (Murakoshi 1988). In contrast to earlier assumptions that early crop cultivation in Tohoku was dominated by dryfield crops, such as millets, barley, wheat and beans (Terasawa 1986), more recent archaeobotanical data suggest that rice was the predominant cultivated crop from its introduction until the end of the Middle Yayoi period (Takase 2011, 2018; Mizoguchi 2013; Nishimura et al. 2018; Sato et al. 2018). Interactions between Jomon communities in northern Tohoku and western Japan are documented by the appearance of Final Jomon pottery (Obora type) in northern Kyushu Yayoi sites and, although not systematically and extensively, the incorporation of shape types of northern Kyushu Early Yayoi pottery (Itazuke type) by Jomon groups in northern Tohoku (Takase 2004). By contrast, such interactions with western Japan are not documented from central Honshu, i.e. the Central Highlands, Kanto and southern Tohoku, where the onset of the Yayoi period is marked by the hybridisation of existing Jomon pottery types and the introduced Ongagawa type (Takase 2004). Although not generally accepted, some scholars believe that social stratification existed during the Jomon period (e.g. Watanabe 1990; Matsumoto 2007), which may have increased over time culminating in the Late and Final stages (Hayden 1995; Matsumoto 2011) with particular development in northern Tohoku and southern Hokkaido (Pearson 2007). Mizoguchi (2013) speculated that Tohoku Jomon groups considered rice as prestigious and introduced it for aggrandising purposes. It is thinkable that the introduction of rice cultivation may have been utilised to increase the power of authorities and thus the prestige and reputation of communities and may have had a competitive effect within the northern Tohoku social network (Hayashi 1986) that also encouraged other groups to introduce rice cultivation. On the other hand, Hirose (1997) and Takase (2004) characterise the Tohoku Jomon before and after the introduction of rice cultivation as socially equal communities without signs of social stratification.

In contrast to their counterparts in Tohoku, communities in the Central Highlands during the Final Jomon to early Middle Yayoi period were characterised by smaller settlements and probably a higher degree of mobility (Shitara 2006) and crop cultivation that was dominated by foxtail and broomcorn millet during the early Yayoi period (Endo and Takase 2011). These dry-field crops better suited a more mobile lifestyle than rice. Compared to rice, the millets are low-demanding and require less labour and organisational efforts, especially when grown in paddy fields. During the Middle Yayoi period, which is represented by Kuribayashi type pottery, rice cultivation appeared in the Central Highlands, although millets remained important (Baba and Endo 2017). It is thinkable that these groups affected crop cultivation patterns at Maenakanishi and other sites in north-western Kanto, as indicated by interactions reflected in pottery assemblages (Kanto Yayoi Culture Research Group 2014).

\section{Conclusions}

Although rice was cultivated at Maenakanishi, where environmental conditions were suitable for paddy field farming, the results of the current archaeobotanical study suggest that it was not the predominant food source. Our findings indicate that millets were a major component in the food economy of local Middle Yayoi populations. Available archaeobotanical data suggest this also for other sites located in different parts of Kanto. However, there is also evidence that other communities focused on rice cultivation and grew millets as minor crops.

A similar situation is encountered regarding the preference between the two millets. At the Maenakanishi/Kitajima complex foxtail millet seems to have been preferred over broomcorn millet. Although at most sites the existing data show more foxtail millet finds, this preference does not apply universally to Yayoi Kanto. Additional statistically significant and directly dated archaeobotanical data from the study region are urgently needed to better understand crop preferences and their driving forces during the Yayoi period.

Our findings provide further evidence that rice did not become the main food source of early agricultural communities all across Japan and that in some regions, such as parts of central Honshu, millets were the preferred crops before rice cultivation was introduced. Food production strategies were diverse and an integral aspect of the regional cultural complexity during the Yayoi period. It appears that crop cultivation patterns varied even on a sub-regional scale and/or within short periods of (sub-) century scale. The substantial reliance on dry-field crops in north-western Kanto during the first half of the Yayoi period may be explained by influence of populations from the northern Central Highlands, who appear to have preferred cultivating foxtail and broomcorn millet over rice. In addition, the available archaeobotanical record from Kanto suggests that over the Early-Middle Yayoi period rice cultivation became generally more important at the expense of millet cultivation.

Acknowledgements This study is a contribution to the interdisciplinary Grant-in-Aid project "Cultural History of PaleoAsia" (grant no. 1802) awarded by the Japanese Ministry of Education, Culture, Sports, Science and Technology (MEXT) and to the German Research Foundation (DFG) project "The spread of agriculture into Far East Eurasia: Timing, pathways, and environmental feedbacks" (DFG TA 540/8-1). The work of C. Leipe is financially supported though a DFG Research Fellowship (LE 3508/2-1). We are grateful to H. Kitagawa (Nagoya University, Japan) for AMS ${ }^{14} \mathrm{C}$ dating of six of the obtained 
carbonised seeds. Thanks to M. Ono and H. Koshitsuka (both Konan Cultural Heritage Center, Kumagaya, Japan) for providing valuable information and literature about Yayoi culture sites in Kumagaya City. We also appreciate support from E.A. Sergusheva (Far Eastern Branch of the Russian Academy of Sciences, Vladivostok, Russia) and R.N. Spengler III (Max Planck Institute for the Science of Human History, Jena, Germany) and are grateful to two anonymous reviewers, who helped to improve the manuscript.

Funding Open Access funding enabled and organized by Projekt DEAL.

Data availability Complete results of the macrobotanical analysis can be found in the electronic supplementary material available from the PANGAEA digital data repository: https://doi.org/10.1594/PANGA EA.912698 (Leipe et al. 2020a).

Open Access This article is licensed under a Creative Commons Attribution 4.0 International License, which permits use, sharing, adaptation, distribution and reproduction in any medium or format, as long as you give appropriate credit to the original author(s) and the source, provide a link to the Creative Commons licence, and indicate if changes were made. The images or other third party material in this article are included in the article's Creative Commons licence, unless indicated otherwise in a credit line to the material. If material is not included in the article's Creative Commons licence and your intended use is not permitted by statutory regulation or exceeds the permitted use, you will need to obtain permission directly from the copyright holder. To view a copy of this licence, visit http://creativecommons.org/licenses/by/4.0/.

\section{References}

Akazawa T (1986) Hunter-gatherer adaptations and the transition to food production in Japan. In: Zvelebil M (ed) Hunters in transition. Cambridge University Press, Cambridge, pp 151-165

Amino Y (1994) Emperor, rice, and commoners. Jpn Stud 14:1-12

Ando H (2014) A critical reconsideration of the criticism on the historical perspective of Japanese history centered on rice cultivation culture. Bull Natl Mus Jpn Hist 185:405-448 (in Japanese with English abstract)

Baba S, Endo E (2017) Archaeobotanical investigation of domesticated cereals on Kuribayashi-type pottery in the middle Yayoi period of the central highland Japan using the Replica-SEM Method. Nat Res Environ Hum 7:1-22 (in Japanese with English abstract)

Barnes GL (2015) Archaeology of East Asia: the rise of civilization in China. Oxbow Books, Oxford, Korea and Japan

Breen J, Teeuwen M (2010) A new history of Shinto. Wiley-Blackwell, Chichester

Bronk Ramsey C (1995) Radiocarbon calibration and analysis of stratigraphy: the OxCal program. Radiocarbon 37:425-430

Crawford GW (2011) Advances in understanding early agriculture in Japan. Curr Anthropol 52(S4):S331-S345

Crawford GW, Lee G-A (2003) Agricultural origins in the Korean Peninsula. Antiquity 77:87-95

Crawford GW, Takamiya H (1990) The origins and implications of late prehistoric plant husbandry in northern Japan. Antiquity 64:889-911

Dal Martello R, Min R, Stevens C, Higham C, Higham T, Qin L, Fuller DQ (2018) Early agriculture at the crossroads of China and Southeast Asia: Archaeobotanical evidence and radiocarbon dates from Baiyangcun, Yunnan. J Archaeol Sci Rep 20:711-721
Endo E (2011) Analysis of plant utilization at the Oki 2 site, Gunma Prefecture using the Replica-SEM method. Cultura Antiqua 63:122-132 (in Japanese)

Endo E (2012) Archaeobotanical research of the Final Jomon and Early Yayoi periods in western Japan using the Replica-SEM method - Second survey: Chugoku and Shikoku regions. In: Takanashi Foundation for Historical Science (ed) Annual report of the Takanashi Foundation for Historical Science. Marujin Holdings, Tokyo, pp 46-53 (in Japanese)

Endo E (2014) Plant cultivation in the Kanto region during the Yayoi period. Seeds Contact 2:16-23 (in Japanese)

Endo E (2015) Diachronic research for domesticated cereals in west part of Gunma Prefecture during the first half of Yayoi period. In: The 30th meeting of the Japanese Association of Historical Botany, Hokkaido Museum, Ebetsu (in Japanese)

Endo E (2016) Reburials and their cultivated cereals. Seeds Contact 3:6-11 (in Japanese)

Endo E (2017) Replica-SEM study on Yayoi pottery excavated from the Nakazatohara site. In: Tomioka City Board of Education (ed) Tomioka City buried cultural heritage excavation report 43: Nakazato Shimohara Site II, Nakazato Nakahara Site II, Nakazatomiyahira Site, Nakasatohara Site, Nihonsugi Site. Tomioka City Board of Education, Tomioka, pp 319-327 (in Japanese)

Endo E (2018) Seed impression analysis of Yayoi pottery excavated from the Ikego site. In: Sugiyama C (ed) A multi-proxy study of food in the Yayoi period: scientific analyses at the Ikego Site. Rokuichi Shobo, Tokyo, pp 89-104 (in Japanese)

Endo E (2019) Yayoi agriculture in the Kanto region. In: Shitara H (ed) The archeology of agricultural complex formation-the beginning of farming. Yuzankaku, Tokyo, pp 111-125 (in Japanese)

Endo E, Ito A (2013) Appearance of crop grains at the southwestern foot of Mt. Hiei: seed impression survey at the Kyoto archaeological site based on the Replica-SEM method. In: Kyoto University Center for Cultural Properties (ed) Kyoto University Campus annual archaeological site survey report. Kyoto University Center for Cultural Properties, Kyoto, pp 181-200 (in Japanese)

Endo E, Takase K (2011) Foxtail millet (Setaria italica (L.) P. Beauv.) and broomcorn millet (Panicum miliaceum L.) of the Final Jomon period in the Ina Basin, central Japan. Q Archaeol Stud 58:74-85 (in Japanese)

Fujio S (2011) The 'new' Yayoi period: paddy field rice cultivation five hundred years earlier. Yoshikawa Kobunkan, Tokyo (in Japanese)

Fujio S (2017) Rethinking the range of the Yayoi culture. Q Archaeol 138:51-54 (in Japanese)

Hayashi K (1986) Kamegaoka and Ongagawa. In: Kondo Y (ed) Japanese archaeology 1. Iwanami Shoten, Tokyo, pp 93-124 (in Japanese)

Hayden B (1995) Pathways to power: principles for creating socioeconomic inequalities. In: Price TD, Feinman GM (eds) Foundations of social inequality. Plenum Press, New York, pp 15-86

Hirose K (1997) New historical image from Jomon to Yayoi. Kadokawa Shoten, Tokyo (in Japanese)

Hosner D, Wagner M, Tarasov PE, Chen X, Leipe C (2016) Spatiotemporal distribution patterns of archaeological sites in China during the Neolithic and Bronze Age: an overview. Holocene 26:1576-1593

Hosoya LA (2009) Sacred commonness: an archaeobotanical approach to Yayoi social stratification: the 'Central Building Model' and the Osaka Ikegami Sone site. In: Ikeya K, Ogawa H, Mitchell P (eds) Interaction between hunter-gatherers and farmers: from prehistory to present. Senri ethnological studies, vol 73. National Museum of Ethnology, Osaka, pp 99-177

Imamura K (1996) Prehistoric Japan: new perspectives on insular East Asia. University of Hawaii Press, Honolulu 
Ishikawa H (1998) Four archaeological regions in the Kanto Plain during the Middle Yayoi period. Sundai Hist Rev 102:83-109 (in Japanese)

Ishikawa H (2008) Regional perspectives and Yayoi period studies. Architecture of Regions and Culture II. Rokuichi Shobo, Tokyo, pp 23-38

Ishikawa $H$ (2011) The emergence of extremely large agrarian villages in the Kanto region and its backgrounds. In: Shitara H, Fujio S, Matsugi T (eds) Studies on the Yayoi period, vol 3. The Yayoi culture divergence. Doseisha, Tokyo, pp 102-113

Ishikawa H (2014) The importance of northern Niigata Prefecture during the Yayoi culture period. In: Niigata Prefecture Board of Education (ed) 1300th anniversary of the Echigo historical province cultural heritage collection. Niigata Prefecture Board of Education, Niigata City, pp 51-64 (in Japanese)

Ishikawa $H$ (2017) How to understand the Yayoi period and its culture as a study of history. Q Archaeol 138:67-70 (in Japanese)

Kanaseki H, Sahara M (1978) The Yayoi period. Asian Persp 19:15-26

Kaner S, Yano K (2015) Early agriculture in Japan. In: Goucher C, Barker G (eds) The Cambridge world history, vol 2. Cambridge University Press, Cambridge, pp 353-386

Kanto Yayoi Culture Research Group (2014) Conversation about the Maenakanishi archaeological site in Kumagaya City: a largescale settlement site of the Yayoi culture period. Rokuichi Shobo, Tokyo (in Japanese)

Kobayashi K (2017) The real age of the Jomon Period: pottery typology and carbon-14. Douseisha, Tokyo (in Japanese)

Konan Cultural Heritage Center (2018) Kumagaya ruins information site. https://www.kumagaya-iseki.jp/. Accessed 3 Aug 2019

Koyama S (1978) Jomon subsistence and population. Senri Ethnol Stud $2: 1-65$

Kumagaya City Board of Education (2015) The history of Kumagaya City, vol 1: archaeology. Kumagaya City Board of Education, Kumagaya (in Japanese)

Kumagaya City Buried Cultural Heritage Center (2008) Kumagaya digital museum. https://www.kumagaya-bunkazai.jp/museum/ index.htm. Accessed 15 June 2019

Kunikita D (2012) Radiocarbon dating. In: Takase K (ed) Fugusawa 1. Fugusawa Site Research Group, Sapporo, pp 193-214 (in Japanese)

Lee G-A, Crawford GW, Liu L, Chen X (2007) Plants and people from the Early Neolithic to Shang periods in North China. Proc Natl Acad Sci USA 104:1087-1092

Lee S, Hasegawa T (2011) Bayesian phylogenetic analysis supports an agricultural origin of Japonic languages. Proc R Soc B-Biol Sci 278:3662-3669

Leipe C, Endo E, Kuramochi S, Wagner M, Tarasov PE (2020a) Archaeobotanical data from the Middle Yayoi culture layers of the 2018 survey sections 2 and 3 of the Maenakanishi site, central Japan. PANGAEA. https://doi.org/10.1594/PANGAEA.912698

Leipe C, Kuramochi S, Wagner M, Tarasov PE (2020b) Ritual practices and social organisation of Middle Yayoi culture communities in the Kanto region, eastern Japan, derived from archaeological and botanical data from the Maenakanishi site. Archaeol Anthropol Sci 12:134

Leipe C, Long T, Sergusheva EA, Wagner M, Tarasov PE (2019) Discontinuous spread of millet agriculture in eastern Asia and prehistoric population dynamics. Sci Adv 5:eaax6225

Liu X, Hunt Harriet V, Jones Martin K (2009) River valleys and foothills: changing archaeological perceptions of North China's earliest farms. Antiquity 83:82-95

Matsumoto N (2007) Development process of religious ideas (comparative cultural theory). In: Kosugi Y, Taniguchi Y, Nishida Y, Mizunoe K, Yano K (eds) Archaeology of the Jomon Period, vol $11-$ mind and faith: religious ideas and social order. Douseisha, Tokyo, pp 210-220 (in Japanese)
Matsumoto N (2011) The cognitive foundation of long-distance interaction and its relation to social contexts. In: Matsumoto N, Bessho $\mathrm{H}$, Tomii M (eds) Coexistence and cultural transmission in East Asia. Left Coast Press, Walnut Creek, pp 31-48

Matsumoto N, Habu J, Matsui A (2017) Subsistence, sedentism, and social complexity among Jomon Hunter-Gatherers of the Japanese Archipelago. In: Habu J, Lape PV, Olsen JW (eds) Handbook of East and Southeast Asian archaeology. Springer, New York, pp $437-450$

Mizoguchi K (2013) The archaeology of Japan—from the earliest rice farming villages to the rise of the state. Cambridge University Press, Cambridge

Murakoshi K (1988) The Sunazawa archaeological site. In: Sahara M, Kaneseki K (eds) Yayoi culture research, vol 10. Yuzankaku, Tokyo, pp 211-213 (in Japanese)

Nakamura Y, Nakazawa M (2014) Study of seed impressions of the Tokushima area excavation earthenware by the replica method. J Archaeol Soc Tokushima 10:47-56 (in Japanese)

Nakayashiki Site Excavation Project Team (2008) Report of the archaeological research at the Nakayashiki site. Department of History and Culture, Showa Women's University, Tokyo (in Japanese)

Nakayashiki Site Excavation Project Team (2010) Report of the archaeological research at the Nakayashiki site II-7th and 8th excavation. Department of History and Culture, Showa Women's University, Tokyo (in Japanese)

Nasu H, Momohara A (2016) The beginnings of rice and millet agriculture in prehistoric Japan. Quat Int 397:504-512

Negita Y (2000) The beginning of rice farming. In: Tsude H, Sahara M (eds) Environment and food production. Shōgakukan, Tokyo (in Japanese)

Nishimura H, Yamashita Y, Ota K et al (2018) Use of cereals from the early to middle Yayoi period in northern Tohoku as indicated by the replication method. In: Kamijo N, Shitara H (eds) The development of agriculture in Eastern Japan: JSPS KAKENHI joint research symposium. Hirosaki University, Hirosaki, pp 34-37 (in Japanese)

Ogata N (1998) The Late Yayoi period at the Tagoyama site in Shiki City: data from house pit no. 21 of site section 31. Arakawa 1:3553 (in Japanese)

Ohnuki-Tierney E (1993) Rice as self: Japanese Identities through Time. Princeton University Press, Princeton

Pearson R (2007) Debating Jomon social complexity. Asian Persp 46:361-388

Reimer PJ, Bard E, Bayliss A et al (2013) IntCal13 and Marine13 radiocarbon age calibration curves $0-50,000$ years cal BP. Radiocarbon 55:1869-1887

Saino H (2005) A study of paddy-fields in the Yayoi period. Cultura Antiqua 57:43-61 (in Japanese)

Saino H (2017) The beginning and the range of the Yayoi culture. Q Archaeol 138:63-66 (in Japanese)

Sato T (1984) Rice caryopses and carbonised rice kernels from the Kamegaoka site, Sawane Locality B. In: Aomori Prefectural Museum Archaeology Report (ed) Kamegaoka Sekki Jidai Iseki. Aomori Prefectural Museum Archaeology report, Aomori City, pp 216-224 (in Japanese)

Sato Y, Sasaki Y, Nasu H, Momohara A (2018) Seed impression replica study in central and southern Tohoku region. In: Kamijo N, Shitara $\mathrm{H}$ (eds) The development of agriculture in Eastern Japan: JSPS KAKENHI joint research symposium. Hirosaki University, Hirosaki, pp 38-43 (in Japanese)

Shinoda K (2004) Ancient DNA analysis of skeletal samples recovered from the Kuma-Nishioda Yayoi Site. Bull Natl Sci Mus Ser D Anthropol 30:1-8

Shitara H (2006) Process of the formation of farming settlements in the Yayoi period in the Kanto region. Bull Natl Mus Jpn Hist 133:109-153 (in Japanese with English abstract) 
Shitara H (2014a) The Jomon and Yayoi societies-latest lectures on Japanese history, vol 4. Keibunsha, Tokyo (in Japanese)

Shitara H (2014b) Yayoi culture as a complex of multiple farming cultures. Bull Natl Mus Jpn Hist 185:449-469 (in Japanese with English abstract)

Shitara H, Takase K (2014) The beginning of cereal cultivation in the South-West Kanto district by the analysis of replica. Bull Natl Mus Jpn Hist 185:511-530 (in Japanese)

Steinhaus W, Kaner S (2016) An illustrated companion to Japanese archaeology. Archaeopress, Oxford

Takahashi R, Koibuchi R, Saeki F, Hagihara Y, Yoneda M, Adachi N, Nara T (2019) Mitochondrial DNA analysis of the human skeletons excavated from the Shomyoji shell midden site, Kanagawa, Japan. Anthropol Sci 127:65-72

Takase K (2004) Sociography of the Yayoi Period in the northeastern Honshu Island. Rokuichi Shobo, Tokyo (in Japanese)

Takase K (2011) How to understand the agriculture of northern Tohoku. In: Shitara H, Fujio S, Matsuki T (eds) Archaeology of the yayoi period, vol 3: diversified yayoi culture. Douseisha, Tokyo, pp 114-128 (in Japanese)

Takase K (2018) Preliminary report of paleoethnobotanical examinations using the replication method in Aomori and Miyagi Prefectures. In: Kamijo N, Shitara H (eds) The development of agriculture in Eastern Japan: JSPS KAKENHI joint research symposium. Hirosaki University, Hirosaki, pp 18-19 (in Japanese)

Terasawa K (1986) Dry-field crops. Q Archaeol 14:23-31 (in Japanese)

Terasawa K (2000) The birth of kingship. Kodansha, Tokyo (in Japanese)

Terasawa K, Terasawa T (1981) Basic studies of Yayoi period plant food-a premise for research of early farming societies, Bulletin of the Archaeological Institute of Kashihara, no. 5. Archaeological Institute of Kashihara, Nara (in Japanese)

Underhill AP (1997) Current issues in Chinese neolithic archaeology. J World Prehist 11:103-160

Von Verschuer C (2016) Rice, agriculture, and the food supply in premodern Japan. Routledge, New York

Wagner M, Tarasov PE (2014) The Neolithic of northern and central China. In: Renfrew C, Bahn P (eds) The Cambridge world prehistory, vol 2, part V: East Asia and the Americas. Cambridge University Press, Cambridge, pp 742-764

Wagner M, Tarasov P, Hosner D, Fleck A, Ehrich R, Chen X, Leipe C (2013) Mapping of the spatial and temporal distribution of archaeological sites of northern China during the Neolithic and Bronze Age. Quat Int 290-291:344-357

Watanabe H (1990) Jomon stratified Society. Rokko Shuppan, Tokyo (in Japanese)

Yamamoto T, Koizumi R (2005) Results of excavation research at Nakayashiki Site, Kanagawa prefecture: carbonized rice and earthen pits in the Early Yayoi period. J Jpn Archaeol Assoc 12:135-147 (in Japanese with English abstract)

Yoshino MM (1980) Natural regions of Japan. GeoJournal 4:161-172

Yoshioka K (1973) Plant geography. Kyoritsu-Shuppan Publishing House, Tokyo (in Japanese)

Zhao Z (2011) New archaeobotanic data for the study of the origins of agriculture in China. Curr Anthropol 52:S295-S306

Publisher's Note Springer Nature remains neutral with regard to jurisdictional claims in published maps and institutional affiliations. 